\title{
IMPACTO DO ABATE DE VACAS PRENHES SOB PARÂMETROS DE CARCAÇA E SUA INFLUÊNCIA NO RESULTADO ECONÔMICO
}

\author{
Aline Souza Sornas ${ }^{1}$, Paulo Rossi Júnior ${ }^{1}$, Fernanda Aparecida Fragoso Moizes ${ }^{1}$ \\ 1 UFPR \\ Correspondência: Aline Souza Sornas: aline.ss@zootecnista.com.br
}

RESUMO: Com o objetivo de avaliar o rendimento e aspectos de qualidade de carcaça de vacas prenhes, e de relacionar estes com o resultado econômico, foram avaliadas 1.000 vacas abatidas em um frigorífico da região metropolitana de Curitiba-PR, destas, 580 prenhes em diferentes estágios de gestação. A necessidade do experimento surgiu para determinar a fase gestacional de forma precisa e associar com os dados individuais de carcaça. Através da medição da coluna vertebral do feto, foi determinada a idade gestacional das vacas prenhes, verificando-se que os parâmetros de gordura de cobertura, idade do animal, peso da carcaça quente e remuneração pela arroba de carcaça não estão relacionados com a idade gestacional. A idade avançada verificada na categoria vazia sugere vacas de descarte, abatidas para garantir a venda em época de melhor remuneração, e no caso da categoria prenhe, para obter maior ganho de peso, visto que a não ocorrência do cio pode favorecer a engorda, porém, só é efetiva no final da gestação, onde a vaca ganha mais peso devido ao maior desenvolvimento fetal, que implica também em maior perda ao descontar o peso do útero e seu conteúdo da carcaça. Através da pesagem do útero e conteúdo, verificou-se que houve queda no rendimento à medida que a gestação evoluía, causando considerável perda ao frigorífico, que ao atribuir o rendimento padrão de $48 \%$ para todas as vacas, acaba absorvendo o prejuízo das prenhes, principalmente em estágio avançado de gestação. Associando a idade gestacional com a perda em reais com base no valor da arroba, é possível penalizar o pecuarista através de desconto. Essa medida poderá incentivar os produtores a melhorar o manejo reprodutivo, e também auxiliará na fiscalização de cumprimento da normativa, diante da recomendação dos órgãos competentes. Palavras-chave: acabamento de gordura; período gestacional; rendimento de carcaça; vaca de descarte

\section{IMPACT OF SLAUGHTER PREGNANT COWS UNDER PARAMETERS OF CARCASS AND ITS INFLUENCE ON ECONOMIC RESULT}

\begin{abstract}
With the objective of evaluate the yield and quality aspects of carcass of pregnant cows, and relate to the economic result, were evaluated 1.000 cows in a fridge in the metropolitan region of Curitiba-PR, these, 580 pregnant at different stages of pregnancy. The need of the experiment was created to determine the gestational stage in a precise form and associate with the individual carcass data. By measuring the spinal column fetal, was determined the gestational age of the pregnant cows, verifying that the parameters of fat cover, age of the animal, carcass weight before cooling and pay for the arroba of carcass are not related to gestational age. The advanced age verified in not pregnant category suggests cull cows, slaughtered to ensure the sale in time for better pay, and in the case of pregnant category, to get greater weight gain, whereas the nonoccurrence of estrus may favor fattening, however, is only effective at the end of pregnancy, when the cow get more weight due to increased fetal development, and also implies greater loss to discount the weight of the uterus and its contents of the carcass. By weighing the uterus and content, it was found that there was a decrease in yield as pregnancy progressed, causing considerable loss in the fridge, which assign to the standard $48 \%$ yield for all cows ends absorbing the loss of pregnant, especially an advanced stage of pregnancy. Associating gestational age with the loss in money based on the value arroba, it is possible to penalize the farmer through discount. This measure will encourage producers to improve reproductive management, and will also assist in overseeing compliance with the regulations, on the recommendation of the competent organs.
\end{abstract}

Key Words: fat finish; gestational period; carcass yield; cow discard 
e sua influência no resultado econômico

\section{INTRODUÇÃO}

O abate de fêmeas bovinas no Brasil representa cerca de $50 \%$ do volume total. É comum que parte destas fêmeas sejam enviadas prenhes ao abate, especialmente em ciclos de baixa oferta de animais, onde há melhor remuneração ao pecuarista (CERVIERE, 2007). Os ciclos caracterizam a sazonalidade da pecuária brasileira, que segundo dados do LAPBOV- Laboratório de Pesquisa em Bovinocultura de corte (2014), durante a entressafra (de junho a novembro), o preço se eleva diante da redução na oferta de animais em consequência da menor produção forrageira. Porém, mesmo durante a safra, quando a procura excede a demanda, os preços tendem a aumentar (SORNAS et al., 2013).

Diante da importância da bovinocultura para o cenário da pecuária nacional, dados do Ministério da Agricultura, Pecuária e Abastecimento apontam que desde 2004 o Brasil se consolidou entre os maiores exportadores de carne bovina do mundo com vendas em mais de 180 países (MAPA, 2013). Com rebanho de 7,72 milhões de cabeças e abate de 2,4 milhões, com 475 mil toneladas de equivalente-carcaça no Paraná, segundo o ANUALPEC de 2013.

Em relação à normatização, 0 RIISPOA (Regulamento de Inspeção Industrial e Sanitária de Produtos de Origem Animal) regulamenta no Art. 113 que deve ser evitado o abate de fêmeas em estado adiantado de gestação (terço final), sendo que as carcaças das vacas devem ser destinadas à esterilização. No entanto, no Brasil, as carcaças que não apresentam evidência de infecção de maneira geral são comercializadas livremente. Segundo o CISPOA (Coordenadoria de Inspeção de Produtos de Origem Animal), relatado por Pereira (2013), o consumo dessa carne é impróprio pelo risco de transmissão de brucelose (zoonose), que pode causar febre de Malta nos humanos (GIUFFRIDA et al., 2010), doença de caráter debilitante e tratamento demorado. O contágio se dá pelo contato direto com animais infectados e fluidos corporais, também pela ingestão de carne ou leite crus. Nos bovinos, as fêmeas prenhes são mais susceptíveis à infecção, causando aborto no terço final da gestação por processos inflamatórios que levam à necrose dos tecidos placentários.

Fisiologicamente, a gestação da vaca de acordo com Frandson et al. (2005) é de 282 dias em uma prenhez a termo. A placentação e a formação dos envoltórios fetais (bolsas amniótica e alantóide) ocorrem durante os primeiros dias de desenvolvimento embrionário (AMARAL et al. 2010), que juntamente com o peso do útero e do feto, podem chegar a $80 \mathrm{~kg}$ e volume de 55 litros no final da gestação (FERREIRA, 2010). Segundo Bacila (2003), em torno do oitavo mês de gestação o feto atinge cerca de $10 \%$ do peso adulto e $30 \%$ no último mês, sendo que $75 \%$ do crescimento fetal ocorre nos dois últimos meses de gestação (FUNSTON et al., 2010), onde há um aporte energético maior para a vaca, a fim de atender as exigências relacionadas ao desenvolvimento do feto, e preparação para a lactação. A EMBRAPA (1998) recomenda que as vacas prenhes sejam manejadas separadas para atender as exigências da categoria e otimizar os recursos forrageiros disponíveis.

Segundo Bridi (2002), vários aspectos podem influenciar na composição da carcaça e na qualidade da carne, como raça, sexo, peso, idade, nutrição e manejo pré-abate. Para Lawrie (2005) a composição dos músculos é alterada com a idade do animal, com aumento relativo da 
gordura intramuscular e diminuição da porcentagem de umidade do músculo conforme a idade avança, seguindo a curva de desenvolvimento (crescimento alométrico), que se inicia pelo esqueleto, seguido pela musculatura e tecido adiposo. A idade é uma avaliação importante para determinar a qualidade da carne e pode ser determinada através da contagem dos pares de dentes incisivos permanentes.

Para Luchiari (2000), nos animais bem acabados a gordura de cobertura que se encontra sob o couro (gordura subcutânea) perfaz a maior parte da gordura da carcaça, e sua deposição é diferenciada em relação à raça, idade, ambiente e sexo, sendo que na fêmea, a proporção de gordura é maior que a de músculo, por amadurecerem e atingirem a fase de engorda mais precocemente. Segundo Haddad et al. (2010) e Pires et al. (2010) a gordura subcutânea exerce importante função no processo de transformação do músculo em carne. Ela atua como isolante térmico para a musculatura durante 0 resfriamento da carcaça, permitindo um resfriamento lento com rápida queda do $\mathrm{pH}$, evitando assim $\mathrm{o}$ encurtamento excessivo das fibras (sarcômeros) que causam o efeito de cold-shortening pela perda da maciez da carne durante a cocção, além de facilitar a ação das calpaínas que promovem a proteólise das fibras musculares, responsável também pela maciez da carne. Quanto maior a espessura de gordura, mais lento é o processo de resfriamento, resultando em menor força de cisalhamento após a maturação (força necessária na mastigação). Porém, quando a espessura de gordura for acima de $6 \mathrm{~mm}$, o rendimento cárneo na desossa diminui por conta dos retalhos que são aparados dos cortes comerciais. Para Müller (1987) a fim de conservar a carcaça e garantir a qualidade final da carne, deve-se proporcionar de 3 a $5 \mathrm{~mm}$ de espessura de gordura.

O rendimento da carcaça bovina é uma medida diretamente relacionada ao aspecto econômico e, consequentemente, de maior interesse dos frigoríficos, que buscam maior rendimento para diluir os custos por quilograma de carne desossada (PIRES et al., 2010; GUERRERO et al., 2013). O rendimento médio de carcaça do rebanho brasileiro é de 53\% (HADDAD et al., 2010), e depende da quantidade de músculo em relação à ossatura e à gordura (BRIDI, 2002).

Muitos pecuaristas enviam as fêmeas ao abate sem saber o diagnóstico de gestação, não raro com a ocorrência de partos em pleno curral de recebimento do frigorífico, infelizmente este é o reflexo de uma pecuária sem manejo adequado, e que representa grande parte da pecuária nacional. Diante deste fato, e a fim de obter maiores informações acerca do abate de fêmeas bovinas prenhes, o presente trabalho tem como objetivo avaliar 0 rendimento e aspectos de qualidade de carcaça de vacas prenhes em diferentes fases de gestação, comparadas a vacas não prenhes, e relacioná-los ao resultado econômico do frigorífico.

\section{MATERIAL E MÉTODOS}

O trabalho foi conduzido em um frigorífico localizado na região metropolitana de Curitiba-PR, que opera sob critérios do SIF (Serviço de Inspeção Federal).

Em uma amostra de 1.000 vacas durante o período compreendido entre 14 de abril a 20 de maio de 2014, foram avaliadas fêmeas vazias e prenhes de diferentes idades e estágios de gestação, conforme normatização seguida pelo frigorífico acerca do manejo pré abate (jejum, repouso e banho de aspersão) e critérios do manejo de abate (atordoamento, 
sangria, retirada de cascos e chifres, esfola, retirada da cabeça, evisceração, divisão longitudinal em duas meias carcaças, toalete, pesagem e resfriamento). Os parâmetros coletados do abate foram: gordura de acabamento, rendimento da carcaça e idade do animal.

Com o uso de uma balança digital, em uma área próxima à mesa de evisceração na linha de abate, a coleta de dados desenvolveu-se da seguinte forma:

- Retirada dos úteros na mesa de evisceração, acomodação em caixas plásticas e identificação com fichas numéricas em série conforme a sequência de abate;

- Uteros não gravídicos: pesagem e descarte;

- Úteros gravídicos: pesagem, abertura na mesa de corte, medição do comprimento do feto, em $\mathrm{cm}$, pela coluna vertebral, da nuca (articulação occipital) até a base da cauda (primeira vértebra coccigiana), conforme metodologia descrita por Ferreira (2010) e descarte.

Utilizou-se a fórmula citada por Noakes (1990):

$$
x=2,5(y+21)
$$

Onde $\mathrm{x}=$ idade fetal em dias e $\mathrm{y}=$ comprimento ápico (crânio)-caudal em $\mathrm{cm}$.

Os dados foram posteriormente complementados com os dados individuais de acordo com o romaneio do frigorífico, com as informações de gordura de acabamento, idade, peso da carcaça quente e preço da arroba paga ao pecuarista. A obtenção da perda por rendimento em porcentagem considerou $48 \%$ de rendimento como padrão para todas as fêmeas.

A idade foi obtida através da contagem de pares de dentes descrita por Luchiari (2000), onde: dentes de leite $=6-20$ meses; 1 par $=2$ anos; 2 pares $=2,5$ anos; 3 pares $=3$ anos e 4 pares $=4$ anos ou mais, e o acabamento de gordura foi obtido através de observação da carcaça quente em $\mathrm{mm}$ de espessura conforme padronização descrita por Felício et al. (2010): $0 \mathrm{~mm}=$ ausente; $1-3 \mathrm{~mm}=$ escassa; $4-6 \mathrm{~mm}=$ mediana; $7-10 \mathrm{~mm}=$ uniforme; acima de $10 \mathrm{~mm}=$ excessiva. Ambas as características retiradas diariamente do romaneio ao fim do abate.

Para análise comparativa dos parâmetros obtidos entre os grupos de vacas prenhes e não prenhes foi realizada a análise de variância (ANOVA).

Foi realizado estudo de correlações entre os parâmetros técnicos e financeiros a fim de determinar uma relação entre idade gestacional e perda $(R \$)$, onde a equação deduzida da análise de regressão por polinômios ortogonais, possibilitou o desconto monetário a ser efetuado para diferentes idades gestacionais.

\section{RESULTADOS E DISCUSSÃO}

A Tabela 1 mostra a comparação da análise obtida entre as vacas vazias (420 animais) e as vacas prenhes (580 animais) em diferentes estágios de gestação, somando-se a amostra de 1.000 animais. Tanto o peso médio da carcaça quente quanto o preço pago ao pecuarista pela arroba da vaca estatisticamente não diferiram. Já 0 peso do útero das vacas prenhes difere das não prenhes neste experimento, bem como a perda em porcentagem e consequentemente a perda em reais, pois fica evidenciado pelo peso do conteúdo do útero gravídico.

Na mesma tabela, os parâmetros de carcaça são mostrados também nas vacas prenhes distribuídas nos três trimestres gestacionais. 


\begin{tabular}{|c|c|c|c|c|c|}
\hline \multirow{2}{*}{$\begin{array}{l}\text { Parâmetros de } \\
\text { carcaça }\end{array}$} & \multirow{2}{*}{ Vazia } & \multirow{2}{*}{ Prenha } & \multicolumn{3}{|c|}{ Idade gestacional } \\
\hline & & & $1^{\circ}$ trimestre & $2^{\circ}$ trimestre & $3^{\circ}$ trimestre \\
\hline Total de animais & 420 & 580 & 125 & 318 & 137 \\
\hline Peso úter o" $(\mathrm{kg})$ & $0,40^{\circ}$ & $14,57^{\circ}$ & 1,34 & 11,92 & 38,51 \\
\hline Compr. feto* $(\mathrm{cm})$ & - & 35,82 & 6,35 & 32,60 & 68,50 \\
\hline Acsbamento- (mm) & $4-6^{\circ}$ & $4-6^{3}$ & 0 & $4-6$ & 4-6 \\
\hline Idade*- (anos) & $4^{3}$ & $4^{3}$ & 4 & 4 & 4 \\
\hline Carcaça quente $-(\mathrm{kg})$ & $222^{\circ}$ & $217^{\circ}$ & 213 & 218 & 217 \\
\hline Preço (RS@) & $111^{\circ}$ & $110^{\circ}$ & 110 & 110 & 110 \\
\hline Perda* (\%) & $0,09^{\circ}$ & $3,07^{\circ}$ & 0,31 & 2,60 & 7,92 \\
\hline Perda* (RS) & $2,96^{\circ}$ & $106,49^{\circ}$ & 9,80 & 87,64 & 282,59 \\
\hline Perda total (RS) & $1.244,20^{\circ}$ & $61.762,27^{\circ}$ & $1.423,60$ & $25.821,13$ & $34.517,54$ \\
\hline
\end{tabular}

Os parâmetros de idade e acabamento de gordura, estatisticamente foram iguais, resultando em 4 pares de dentes (4 anos ou mais) e acabamento de gordura mediano (4-6mm de espessura), tanto para vacas vazias, como para as prenhes distribuídas por trimestre, evidenciando que os parâmetros analisados não tiveram relação com a prenhez, nem com o estágio da gestação, o que se explica pela falta de manejo adequado por categoria. Kreikemeier \& Unruh (1993) ao comparar características de carcaça de 8.292 novilhas, encontraram menor valor médio para o peso das carcaças de novilhas prenhes (4,5 kg mais leves) e $2 \mathrm{~cm}$ a mais de espessura de gordura, com melhor classificação. Porém, os autores concluem que apesar da carcaça de novilhas prenhes apresentarem melhor classificação segundo os padrões americanos, não compensa devido ao menor rendimento da carcaça e maior espessura de gordura. Também Grassi \& Müller (1991) avaliaram o desempenho de características de carcaça de vacas de descarte e concluíram que as vacas prenhes, em comparação com vacas vazias e vacas castradas, apresentaram maior ganho de peso médio diário e maior espessura de gordura, porém, também com menor rendimento

A idade avançada indica o abate de fêmeas provenientes de descarte, e está relacionado com o período em que decorreu o experimento, entre os meses de abril e maio, meses em que historicamente ocorre o descarte das fêmeas que não emprenharam, segundo dados do LAPBOV - Laboratório de Pesquisa em Bovinocultura de corte (2014). De acordo com Rezende (2012), as carcaças de vacas de descarte são destinadas ao mercado interno, com qualidade inferior e apresentando baixos rendimentos.

Comumente as vacas de descarte por idade avançada são emprenhadas principalmente por duas razões: engorda e facilidade de manejo. A ilusão de engorda verificada durante a gestação é atribuída apenas ao fato do animal não entrar mais em cio (período em que a vaca reduz o consumo, segundo Amaral et al., 2010) assim, não interfere no consumo normal, e o aumento efetivo no ganho de peso para atender o maior aporte energético só é verificado no final da gestação (HADDAD et al., 2010; FUNSTON et al., 2010; BACILA, 2003), porém, a eficiência alimentar pode ser reduzida por causa do desvio de nutrientes para o feto (JIM et al., 1991) e como o feto e o conteúdo uterino ficam bastante pesados nesta fase, a perda por rendimento será maior. A facilidade de manejo está relacionada também com a não ocorrência de cio, onde o pecuarista pode misturar os lotes inclusive com touros, sem prejudicar o consumo das vacas pelo estresse gerado durante 0 cio. Ambas as situações estão relacionadas com os picos de demanda e oferta, quando a remuneração é boa, os animais são abatidos para garantir o preço, quando a demanda cai, as fêmeas prenhes são abatidas para liberar pastagens e reduzir estoque.

A maior concentração de animais prenhes encontra-se entre $04^{\circ}$ e $05^{\circ}$ mês de gestação (ou entre 91 e 150 dias), representando $21 \%$ e $22 \%$ respectivamente. $O$ peso do útero e o comprimento fetal vão aumentando ao longo da gestação, verificando-se 
maiores valores enquanto mais se aproxima do parto, com peso variando de $0,45 \mathrm{~kg}$ à $58,00 \mathrm{~kg}$ e comprimento entre $3 \mathrm{~cm}$ e $91 \mathrm{~cm}$ no total.

Em relação ao rendimento, as maiores perdas médias tanto em percentagem como em reais são verificadas a partir do segundo trimestre gestacional, sendo mais expressivas no terço final, representando até cerca de $8 \%$ do total do peso da carcaça. Meyer (2005) e Wren (2008) também encontraram menor desempenho na carcaça de vacas prenhes em comparação às não prenhes, que apresentaram menor ganho de peso em carcaça (redução de 12,2\%), menor rendimento (5,5\% menos), e pior conversão alimentar (13,3\% maior), além do aumento na probabilidade de infecções e perda por morte no parto, representando a classe com maior perda econômica segundo Wren (2008). Porém, em experimento avaliando a eficiência de novilhas castradas, vazias e prenhes, Hart et al. (1940) constataram que não houve redução no rendimento de carcaça de novilhas até 175 dias de gestação, com o peso do útero e conteúdo variando entre 6 a 8kg, diferente do encontrado neste experimento, que variou entre 18 e $58 \mathrm{~kg}$ para o terço final.

Seguindo as definições de Bourdon (1997), houve alta correlação entre a idade gestacional em dias com o peso do útero $(0,92)$ e o comprimento do feto $(0,99)$, também com a perda em rendimento $(0,93)$ e em reais $(0,94)$. Demonstrando que quanto mais avançada a gestação, maior o feto e o peso do útero, e maiores as perdas. Já a baixa correlação encontrada entre 0 preço pago por arroba e a perda em reais $(0,05)$, evidencia que as perdas não são repassadas para o produtor, e sim absorvidas pelo frigorífico, pois ao aplicar 0 rendimento padrão para fêmeas de $48 \%$ ao animal vivo, não verifica as perdas ocasionadas pela prenhez. As perdas monetárias durante o experimento, estendidas para 0 período de um ano poderia representar um total de $R \$ 741.147,00$.

Diante dos resultados de correlação, foi feita uma análise de regressão por polinômios ortogonais, traçando um gráfico de dispersão com comportamento linear. O coeficiente de determinação explica $89 \%$ da variação dos dados (preço em relação à idade gestacional).

Com a equação de regressão gerada: $y=1,7553 x-133,13$, onde y é 0 preço a descontar $\mathrm{e} x$ é a idade gestacional, foi possível montar uma tabela básica de descontos em relação à idade gestacional, que o frigorífico pode usar como ferramenta com base no preço da arroba praticado (Tabela 2).

\begin{tabular}{lc} 
Tabela 2 - Desconto por idade gestacional \\
\hline Idade G estacional & Desconto (R\$ por an imal) ${ }^{*}$ \\
\hline Até 90 dias (ou $1^{\circ}$ trimestre) & 24,85 \\
$90-180$ dias (ou $2^{\circ}$ trimestre) & 182,82 \\
A partir de 180 dias (ou $3^{\circ}$ trimestre) & 340,80 \\
\hline${ }^{*}$ Com base no valor da arroba de R\$110,19.
\end{tabular}

A separação por semestre facilita o trabalho prático no frigorífico, pois pode ser executado de maneira visual. Durante o experimento, foi elaborado um banco fotográfico para auxiliar na identificação da fase gestacional, demonstrado nas Figuras 1, 2 e 3.

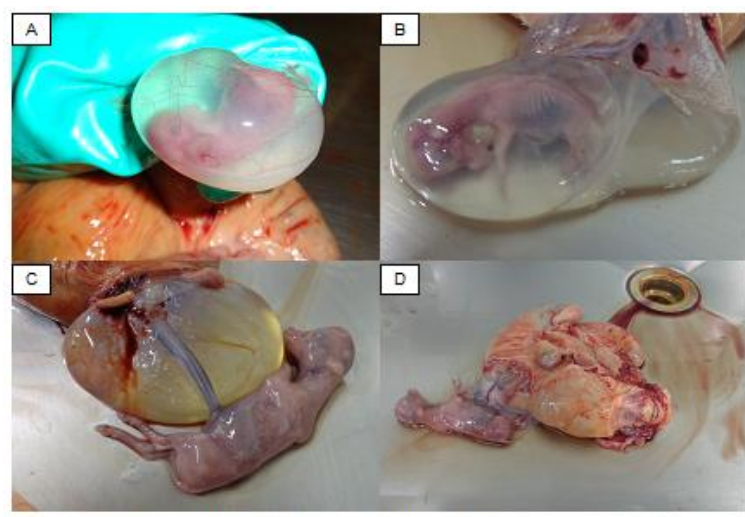

Figu ra 1 - Padrão fotográfico do primeiro trimestre. A:feto de 1 més; $B$ : feto de 2 meses; C: feto de 3 meses; D: útero contendo feto de 2 meses. 


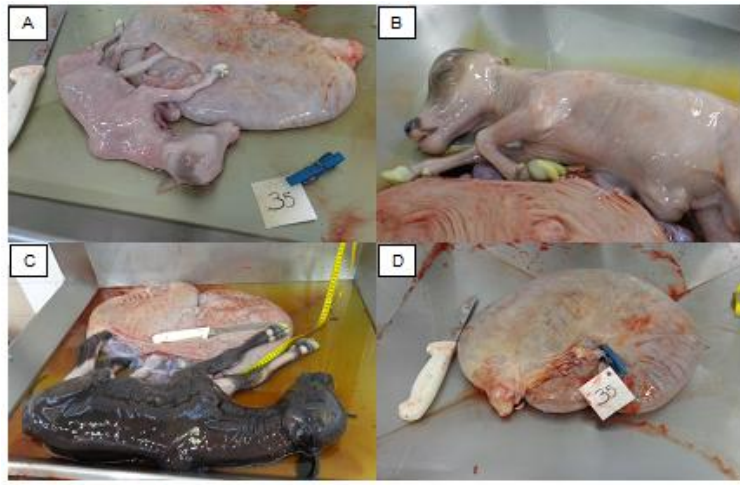

Figura 2 - Padrão fotográfico do segundo trimestre.

A. feto de 4 meses: $B$ : feto de 5 meses: C: feto de 8 mese: D. itero contendo feto de 4 meses.

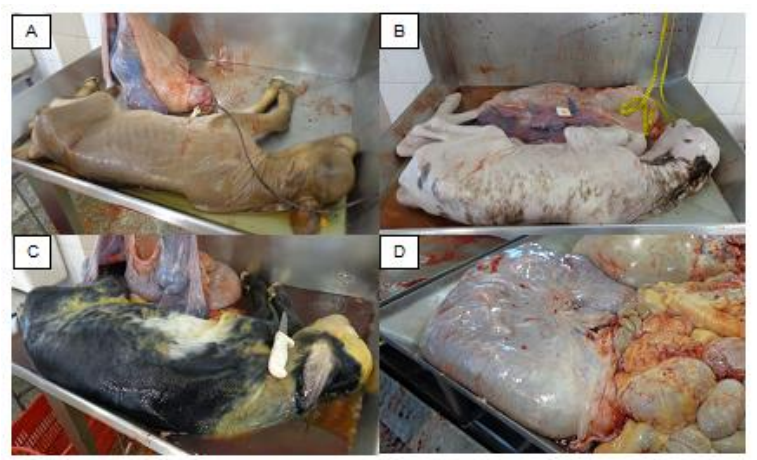

Figura 3 - Padrão fotográfico do terceiro trimestre.

A.feto de 7 meses; B: feto de 8 meses; C: feto de 9 meses; D: útero contendo feto de 8 meses.

\section{CONCLUSÃO}

O maior impacto refere-se à queda significativa de rendimento à medida que a gestação evolui, causando perda monetária ao frigorífico, que ao atribuir o rendimento padrão de $48 \%$ a todas as fêmeas abatidas, absorve o prejuízo das fêmeas prenhes. Os demais parâmetros de carcaça referentes ao acabamento de gordura, idade do animal, peso da carcaça quente e preço pago por arroba não tiveram relação com a prenhez, nem com o estágio da gestação, já a idade avançada verificada em ambas as categorias evidencia o abate de fêmeas de descarte, relacionado com a sazonalidade da pecuária em relação ao preço. Através da tabela de descontos, usando como base o preço da arroba pago ao pecuarista, o frigorífico poderá penalizar o pecuarista que enviar vacas prenhes ao abate, principalmente as de gestação avançada. Essa medida, a longo e médio prazos, poderá incentivar os produtores a melhorar o manejo de categoria, e também auxiliará na fiscalização de cumprimento da normativa, diante da recomendação dos órgãos competentes.

\section{REFERÊNCIAS}

AMARAL, T.B.; FERNANDES, C.E.; ALMEIDA, C.Q. et al. Reprodução. In: PIRES, A.V.

Bovinocultura de corte. Volume I. Piracicaba: FEALQ, 2010, Seção VII, p.513-709.

ANUALPEC: Anuário da Pecuária Brasileira. São Paulo: Instituto FNJ Consultoria \& Comércio, 2013.

BACILA, M. Bioquímica Veterinária. In 0 Desenvolvimento Fetal. 2.ed. São Paulo: Robe Editorial, 2003. p.415-420.

BOURDON, R.M. Understanding animal breeding. New Jersey: Prentice Hall, 1997. p.523.

BRASIL. Ministério da Agricultura. Departamento de Defesa e Inspeção Agropecuária. Regulamento de Inspeção Industrial e Sanitária de Produtos de Origem Animal - RIISPOA. In _. Inspeção Industrial e Sanitária de Carnes e Derivados. São Paulo: Inspetoria do SIPAMA, 1968. Título VII, p.26-41. Disponível em:

<http://www.bahianet.com.br/crmvba/riispoa2.ht $\mathrm{m}>$. Acesso em: 17/03/2014.

BRIDI A.M. Normas de Avaliação, Classificação e Tipificação de Carnes e Carcaças. Univ. Est. Londrina. 2002.

CERVIERI, R. Engorda de novilhas prenhas e suas implicações sobre as características de carcaça. In: Beef Point, 29/03/2007. Disponível em: <http://www.beefpoint.com.br/sistemas-deproducao/>. Acesso em 16/03/2014.

EMBRAPA. Empresa Brasileira de Pesquisa Agropecuária. Centro de Pesquisa de Pecuária dos Campos Sulbrasileiros. Produção de Carne de Qualidade para o Rio Grande do Sul, Santa Catarina e Paraná. Bagé, RS, 1998. $121 \mathrm{p}$.

FERREIRA, A. de M. Gestação em bovinos. In: Reprodução da Fêmea Bovina: Fisiologia aplicada. Juiz de Fora, MG: Edição do autor, 2010, Cap. IX, p.345-394. 
Impacto do abate de vacas prenhes sob parâmetros de carcaça e sua influência no resultado econômico

FRANDSON, R.D.; LEE WILKE, W.; DEE

FAILS, A. Anatomia e Fisiologia dos Animais de

Fazenda. In Prenhez e parto. 6.ed. Rio de Janeiro: Guanabara Koogan, 2005. Cap.28, p.390-398.

FUNSTON, R.N.; LARSON, D.L.; VONNAHME, K.A. Efeito da nutrição materna sobre o desenvolvimento fetal e pós-natal: Implicações na produção de gado de corte. In: PIRES, A.V. Bovinocultura de corte. Volume II. Piracicaba: FEALQ, 2010, Cap. 72, p.1463-1478.

GIUFFRIDA, R.; PAES, A.C.; da SILVA, R.C. Doenças infecciosas da reprodução. In: PIRES, A.V. Bovinocultura de corte. Volume II. Piracicaba: FEALQ, 2010, Cap. 51, p.959-992.

GRASSI, C.; MÜLLER, L. Efeito do manejo de vacas de descarte no desempenho e nas características da carcaça. Pesq. Agropec. Bras. v.26, n.8, p.1175-1181, ago 1991.

GUERRERO, A.; PRADO, I.N.; VALERO, M.V. et al. Calidad de La carne de bovino de animales procedentes de sistemas intensivos, semi intensivos y pastoreo. In: SIMPOSIO DE PRODUÇÂO ANIMAL A PASTO, II., 2013, Londrina. Anais... Londrina: Universidade Estadual de Londrina, 2013. p.289-312.

HADDAD, C.M.; MENDES, C.Q.; CALEGARE, L. et al. Cria e Recria. In: PIRES, A.V.

Bovinocultura de corte. Volume I. Piracicaba: FEALQ, 2010, Seção IV, p.129-198.

HART, G.H.; GUILBERT, H.R.; COLE, H.H. The relative efficiency of spayed, open and bred heifers in the feedlot. Bulletin California Agricultural Experimental Station. v.645, p.120, 1940 .

JIM, G.K.; RIBBLE, C.S.; GUICHON, P.T et al. The relative economics of feeding open, aborted, and pregnant feedlot heifers. The Canadian Veterinary Journal, v.32, p.613-617, 1991.

KREIKEMEIER, K.K.; UNRUH, J.A. Carcass traits and the occurence of dark cutters in pregnant and nonpregnant feedlot heifers. Journal of Animal Science. v.71, n.7, p.16991703, 1993.

LAPBOV. Laboratório de Pesquisa em Bovinocultura de corte. Disponível em: $<$ http://www.lapbov.ufpr.br/>. Acesso em 28/05/2014.
LAWRIE,R.A. Ciência da carne. 6. ed. - Porto Alegre: Artmed, 2005. 384p.

\section{LUCHIARI FILHO, A. Pecuária da carne} bovina. 1.ed. - São Paulo: A. Luchiari Filho, 2000. 134p.

MAPA. Ministério da Agricultura Pecuária e Abastecimento. Bovinos e Bubalinos, 2013. Disponível em:

<http://www.agricultura.gov.br/animal/espécies/b ovinosebubalinos>. Acesso em 25/03/2014.

MEYER, D.B. Spaying Pays. In: Beef Magazine, 2005. Disponível em: <http://www.gov.on.ca.>. Acesso em 08/04/2014.

MÜLLER, L. Normas para avaliação de carcaças e concurso de carcaça de novilhos. 2.ed. Santa Maria: Universidade Federal de Santa Maria, 1987. 31p.

NOAKES, D. E. Fertilidade e obstetrícia em bovinos. São Paulo: Livraria Varela, 1990. 139p.

PEREIRA, C. Cerco ao abate de vacas prenhes. In: Correio do Povo - RS, 11/02/2013. Disponível em: <http://www.interjornal.com.br>. Acesso em: 17/03/2014.

PIRES, P.P.; MELO, T.P. de O.; de FELÍCIO, P.E. et al. Carne. In: PIRES, A.V.

Bovinocultura de corte. Volume II. Piracicaba: FEALQ, 2010, Seção XI, p.1253-1320.

REZENDE, M. A. Características de carcaça e qualidade da carne de vacas de descarte submetidas a duas velocidades de ganho de peso. 2012. Dourados, MS, 53f. Dissertação (Mestrado em Zootecnia)- Curso de Pósgraduação em Zootecnia, Universidade Federal da Grande Dourados.

SORNAS, A. S. et al. Informativo mensal de dezembro. In: LAPBOV- Laboratório de Pesquisa em Bovinocultura de corte. No. 21, 2013, p.01-05. Disponível em:

<http://www.lapbov.ufpr.br/>. Acesso em 15/03/2014.

WREN, G. Managing pregnant feedlot heifers. In: Drovers Cattle Network, 2008. Disponível em: $<\mathrm{http}: / /$ www.cattlenetwork.com/bovine-vet/bvmagazine/managing-pregnant-feedlot-heifers $>$. Acesso em 7/04/2014. 